\title{
Adequacy of prenatal care among women living with human immunodeficiency virus: a population-based study
}

Ryan $\mathrm{Ng}^{1}$, Erin M Macdonald ${ }^{1}$, Mona R Loutfy, $1,2,3,4$, Mark H Yudin $5,6,7$, Janet Raboud ${ }^{1,8,9}$, Khatundi-Irene Masinde ${ }^{4}$, Ahmed M Bayoumi ${ }^{1,2,3,5,6}$, Wangari E Tharao ${ }^{10}$, Jason Brophy ${ }^{11}$, Richard H Glazier ${ }^{1,25,6,9,9,12}$ and Tony Antoniou ${ }^{1,5,12^{*}}$

\begin{abstract}
Background: Prenatal care reduces perinatal morbidity. However, there are no population-based studies examining the adequacy of prenatal care among women living with HIV. Accordingly, we compared the prevalence of adequate prenatal care among women living with and without HIV infection in Ontario, Canada.

Methods: Using administrative data in a universal single-payer setting, we determined the proportions of women initiating care in the first trimester and receiving adequate prenatal care according to the Revised-Graduated Prenatal Care Utilization Index. We also determined the proportion of women with HIV receiving adequate prenatal care by immigration status. We used generalized estimating equations with a logit link function to derive adjusted odds ratios (aORs) and $95 \%$ confidence intervals (Cl) for all analyses.

Results: Between April 1, 2002 and March 31, 2011, a total of 1,132,135 pregnancies were available for analysis, of which 634 (0.06 \%) were among women living with HIV. Following multivariable adjustment, women living with HIV were less likely to receive adequate prenatal care (36.1\% versus $43.3 \%$; aOR $0.74,95 \% \mathrm{Cl} 0.62$ to 0.88 ) or initiate prenatal care in the first trimester ( $50.8 \%$ versus $70.0 \%$; aOR $0.51,95 \% \mathrm{Cl} 0.43$ to 0.60 ) than women without HIV. Among women with HIV, recent (i.e. $\leq 5$ years) immigrants from Africa and the Caribbean were less likely to receive adequate prenatal care (25.5 \% versus $38.5 \%$; adjusted odds ratio $0.51 ; 95 \% \mathrm{Cl}, 0.32$ to 0.81 ) than Canadian-born women.
\end{abstract}

Conclusion: Despite universal health care, disparities exist in the receipt of adequate prenatal care between women living with and without HIV. Interventions are required to ensure that women with HIV receive timely and adequate prenatal care.

Keywords: Prenatal care, HIV, Disparity, Population-based, Immigrant

\section{Background}

Prenatal care is among the most widely used preventive health care service in developed countries [1].The Society of Obstetricians and Gynaecologists of Canada recommends that prenatal care visits are scheduled every 4 to 6 weeks during early pregnancy, every 2 to 3 weeks after 30 weeks' gestation, and every 1 to 2 weeks after 36 weeks' gestation [2]. Early initiation of and retention in prenatal care provides expectant mothers access to a variety of

\footnotetext{
* Correspondence: tantoniou@smh.ca

'Institute for Clinical Evaluative Sciences, Toronto, Ontario, Canada

5 Li Ka Shing Knowledge Institute, St. Michael's Hospital, Toronto, Ontario, Canada

Full list of author information is available at the end of the article
}

medical, nutritional and educational interventions directed towards optimizing infant health and has been associated with reduced risks of adverse neonatal and maternal outcomes [3-6]. However, despite widespread endorsement by national medical societies [7, 8], several studies have suggested that disparities exist with respect to the receipt of adequate prenatal care, commonly defined as the initiation of care in the first trimester or according to a prenatal care utilization index that considers the number and periodicity of prenatal care visits in relation to the gestational age of the newborn at delivery [9]. Specifically, higher parity, belonging to a minority ethnic group and low socioeconomic status have consistently been associated with inadequate utilization of prenatal

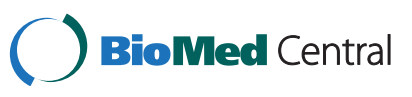


care services [10-12]. In addition, women who have immigrated to Western countries are less likely to initiate prenatal care in the first trimester and attend prenatal appointments relative to non-immigrant women for reasons that include poor language proficiency, community isolation and institutionalized racism [13-18]. In the context of HIV-infection, these factors intersect with multiple forms of perceived and enacted stigma within the health care system to further undermine engagement with health services and preconception counselling [19-21]. Notably, several studies have found that approximately $50 \%$ of women with HIV do not receive reproductive counselling from their health care providers [22-24]. Furthermore, previous research has shown that $54 \%$ of pregnancies among a cohort of women living with HIV in Ontario were unplanned, compared with $30 \%$ in the general Ontario population [25]. These findings are concerning because unintended pregnancies delay the initiation of prenatal care, the timely initiation of which has been shown to reduce the risks of preterm births and low birth weight infants among women with HIV [26, 27].

Despite these data, little is known about the impact of maternal HIV infection on the use of prenatal care services. Studies conducted during the early years of the epidemic found that up to two-thirds of women living with HIV in the United States did not receive adequate prenatal care as assessed with a prenatal care utilization index, but inferences from these studies are limited by a lack of generalizability to contemporary HIV care [28]. To our knowledge, there are no population-based studies examining the adequacy of prenatal care for women with HIV in a setting of universal health insurance. Accordingly, we studied the adequacy of prenatal care in women living with HIV relative to women not living with HIV in Ontario, Canada. Because women originally from Africa and the Caribbean account for an increasing proportion of women living with HIV who are having children in Ontario $(26.7 \%$ in $2002 / 2003$ to $51.6 \%$ in 2009/10), we also examined the adequacy of prenatal care among women with HIV originally from these regions [29]. In light of research describing stigma and factors related to immigration as barriers to accessing care, we hypothesized that women with HIV would be less likely to receive adequate prenatal care than women without HIV. Similarly, we hypothesized that women with HIV who were originally from Africa and the Caribbean would be less likely to receive adequate prenatal care than non-immigrant women.

\section{Methods}

\section{Setting}

We conducted a population-based study of pregnancies among women living with and without HIV in Ontario between April 1, 2002 and March 31, 2011. Ontario has a universal single-payer, government administered health care system. Accordingly, all permanent residents are eligible to receive publicly funded physician and hospital care, including prenatal care, without copayments or deductibles. This project was approved by the Research Ethics Board of the Sunnybrook Health Sciences Centre, Toronto, Ontario.

\section{Data sources}

We used Ontario's administrative health databases, which were held securely in linkable files without any direct personal identifiers, and analyzed at the Institute for Clinical Evaluative Sciences. Specifically, we identified all pregnancies among Ontario women between the ages of 18 and 49 during the study period using the MOMBABY database, which deterministically links the Canadian Institute for Health Information Discharge Abstract Database inpatient admission records of all mothers and their newborn infants from 2002/03 onward. From within this cohort, we identified births to women living with HIV using the Ontario HIV Database, an administrative data registry of Ontario residents with diagnosed HIV infection which was generated using a previously validated casefinding algorithm [30]. We obtained demographic information from the Registered Persons Database, a registry of all Ontario residents eligible for provincial health insurance. We used the Ontario Health Insurance Plan (OHIP) database to identify physician claims for prenatal visits and obtained hospitalization data from the Canadian Institute for Health Information Discharge Abstract Database. Finally, we used the Citizenship and Immigration Canada Database to identify women who had immigrated to Ontario and their country of origin. These databases were linked in an anonymous fashion using encrypted health card numbers, and are routinely used for populationbased research examining health care delivery and health outcomes, including pregnancy outcomes [31,32].

\section{Outcome}

The primary outcome was the receipt of adequate prenatal care, determined using the Revised-Graduated Prenatal Care Utilization Index (R-GINDEX) [33]. The R-GINDEX, which is based on recommendations of the American College of Obstetricians and Gynecologists, classifies the adequacy of care into one of six categories (inadequate, adequate, intermediate, intensive, no care or missing) based on the number of prenatal care visits, the gestational age of the newborn at birth and the date prenatal care was initiated. For example, women who give birth at 40 weeks gestation and who initiate care in the first trimester would be classified as having received adequate, intermediate or inadequate care if they received between 13 and 16 visits, 8 and 12 visits or fewer than 8 visits, respectively (see Additional file 1: Table S1 for examples of 
R-GINDEX categories for 28-, 32-, 36- and 40-week deliveries). We determined the gestational age of the newborn from the MOMBABY database and used the OHIP database to identify all prenatal office visits to primary care physicians and obstetrician/gynecologists. We did not include visits where only screening procedures such as amniocentesis or ultrasounds were performed. We classified women in the 'adequate' and 'intensive' categories as receiving adequate prenatal care, and women in the 'inadequate, 'no care' and 'intermediate' categories as receiving inadequate prenatal care. We also determined the proportions of women living with and without HIV who initiated care in the first trimester, because this is a traditionally used measure of prenatal care adequacy [34-36]. Women with missing prenatal care (i.e. missing gestational age) according to the R-GINDEX were not included in the analyses.

\section{Statistical analyses}

We compared baseline characteristics of pregnancies to mothers living with and without HIV using one-way analysis of variance for continuous variables, CochraneArmitage tests for ordinal variables and chi-square tests for categorical variables. In separate analyses, we compared the proportions of women living with and without HIV who received adequate prenatal care according to the R-GINDEX and who initiated prenatal care in the first trimester using multivariable general estimating equations with a logit link function and an exchangeable correlation structure to account for multiple pregnancies from the same woman during the follow-up period. We adjusted models for variables known to influence the use of prenatal care services, including age, parity, multiple versus singleton birth, co-morbid disease, immigration status, and socioeconomic status. We categorized time since immigration to Ontario as recent (i.e. $\leq 5$ years) or nonrecent (i.e. $>5$ years). We used Johns Hopkins Aggregated Diagnosis Groups, which range from 0 (no diagnosis groups) to a maximum of 32 distinct diagnosis groups, to adjust for differences in comorbidity between women with and without HIV [37]. We used the Ontario Marginalization Index as a measure of maternal socioeconomic status [38]. Specifically, we derived quintiles of neighborhood material deprivation and residential instability using postal code data from the Registered Persons Database and the 2001 census of Canada. For example, an individual who lives in a neighborhood in the fifth quintile on the material deprivation scale resides in one of the $20 \%$ most deprived areas in Ontario. Residential instability includes seven census measures: percentage living alone, percentage youth 5-15 years, persons per dwelling, percentage living in apartment buildings, percentage married, percentage home ownership, and percentage moving within the last 5 years [38]. Similarly, material deprivation includes six census measures, expressed as proportions: aged $\geq 20$ years without high school graduation, lone parent families, population receiving government transfer payments, aged $\geq 15$ and unemployed, living below the low income cut-off, and homes needing major repairs [38]. In separate models, we examined whether region of origin and time since immigration were associated with receiving adequate prenatal care only among women living with HIV. All analyses were performed using SAS version 9.3 (Cary, NC).

\section{Results}

We identified 1,133,522 pregnancies between April1, 2002 and March 31, 2012. After excluding 1,387 (0.1\%) pregnancies for which the R-GINDEX could not be determined (all to HIV-negative women), 1,132,135 pregnancies were available for analysis, of which 634 (0.06\%) were among women living with HIV. Relative to women without HIV, women living with HIV were more likely to be immigrants $(48.1 \%$ vs. $25.9 \%$; p $<0.001)$ and live in neighborhoods that were the most deprived $(41.1 \%$ vs. $16.2 \% ; \mathrm{p}<0.001)$ and with the greatest residential instability ( $39.9 \%$ vs. $17.9 \%$; $<$ 0.001) (Table 1$)$. Women with HIV were also more likely to have a pregnancy resulting in multiple births (3.0 \% vs. $1.8 \%$; $=0.02)$ and a greater co-morbidity burden, as demonstrated by the median number of Aggregated Diagnosis Groups in the preceding year [6 (interquartile range 5.0 to 9.0 ) vs. 4.0 (interquartile range 3.0 to 6.0); $\mathrm{p}<0.001$ ] (Table 1).

The median number of prenatal care visits by women living with and without HIV was 11.0 (interquartile range 8.0 to 13.0 ) and 11.0 (interquartile range 9.0 to $13.0)$, respectively $(\mathrm{p}<0.001)$. However, the proportion of women initiating prenatal care in the first trimester $(50.8 \%$ vs. $70.0 \%$; p < 0.001$)$ was significantly lower among women living with HIV. When classified using the R-GINDEX, adequate prenatal care was received by $36.1 \%$ and $43.3 \%$ of women living with and without HIV, respectively $(\mathrm{p}<0.001)$.

Following multivariable adjustment, women living with HIV were less likely to receive adequate prenatal care [adjusted odds ratio (aOR) 0.74; $95 \%$ confidence interval $(\mathrm{CI})$ 0.62 to 0.88 ] or initiate prenatal care in the first trimester (aOR 0.51; $95 \%$ CI 0.43 to 0.60 ) than women living without HIV (Tables 2 and 3). The odds of receiving adequate prenatal care and care in the first trimester also decreased with increasing neighborhood deprivation (Tables 2 and 3). Among women with HIV, recent (i.e. $\leq 5$ years) immigrants from Africa and the Caribbean were less likely to receive adequate prenatal care $(25.5 \%$ vs. $38.5 \%$; aOR $0.51 ; 95 \%$ CI 0.32 to 0.81 ) or begin care in the first trimester $(35.0 \%$ vs. $56.5 \%$; aOR $0.44 ; 95 \%$ CI 0.29 to 0.66$)$ than non-immigrant-born women (Additional file 2: Table S2 and Additional file 3: Table S3). 
Table 1 Baseline characteristics of pregnancies according to HIV status

\begin{tabular}{|c|c|c|c|}
\hline Characteristic & $\begin{array}{l}\text { HIV } \\
(n=634)\end{array}$ & $\begin{array}{l}\text { Non-HIV } \\
(n=1,131,501)\end{array}$ & p-value \\
\hline Mean age \pm SD (years) & $30.8 \pm 5.2$ & $30.1 \pm 5.2$ & 0.001 \\
\hline 18 to 34 years & $470(74.1 \%)$ & $894,604(79.1 \%)$ & 0.002 \\
\hline 35 to 49 years & $164(25.9 \%)$ & $236,897(20.9 \%)$ & \\
\hline \multicolumn{4}{|l|}{ Aggregated Diagnosis Groups } \\
\hline Median (IQR) & $6.0(5.0-9.0)$ & $4.0(3.0-6.0)$ & $<0.001$ \\
\hline 0 to 5 & $238(37.5 \%)$ & $786,857(69.5 \%)$ & $<0.001$ \\
\hline 6 to 10 & $331(52.2 \%)$ & $330,199(29.2 \%)$ & \\
\hline 11 or more & $65(10.3 \%)$ & $14,445(1.3 \%)$ & \\
\hline Immigration Status, No. (\%) & & & $<0.001$ \\
\hline Non-immigrant & $329(51.9 \%)$ & $839,572(74.2 \%)$ & \\
\hline Non-recent immigrant, Africa or Caribbean & $97(15.3 \%)$ & $23,788(2.1 \%)$ & \\
\hline Non-recent immigrant, other world regions & $28(4.4 \%)$ & $108,338(9.6 \%)$ & \\
\hline Recent immigrant, Africa or Caribbean & $157(24.8 \%)$ & $15,393(1.4 \%)$ & \\
\hline Recent immigrant, other world regions & $23(3.6 \%)$ & $144,410(12.8 \%)$ & \\
\hline Material Deprivation Income Quintile, No. (\%) & & & $<0.001$ \\
\hline 1 (lowest) & $68(10.7 \%)$ & $296,497(26.2 \%)$ & \\
\hline 2 & $72(11.4 \%)$ & $232,786(20.6 \%)$ & \\
\hline 3 & $98(15.5 \%)$ & $213,374(18.9 \%)$ & \\
\hline 4 & $117(18.5 \%)$ & $190,740(16.9 \%)$ & \\
\hline 5 & $261(41.2 \%)$ & $183,633(16.2 \%)$ & \\
\hline Residential Instability Quintile, No. (\%) & & & $<0.001$ \\
\hline 1 (lowest) & $77(12.1 \%)$ & $303,196(26.8 \%)$ & \\
\hline 2 & $72(11.4 \%)$ & $228,544(20.2 \%)$ & \\
\hline 3 & $69(10.9 \%)$ & $168,253(14.9 \%)$ & \\
\hline 4 & $145(22.9 \%)$ & $214,623(19.0 \%)$ & \\
\hline 5 & $253(39.9 \%)$ & $202,414(17.9 \%)$ & \\
\hline Multiple birth & 19 (3.0 \%) & $19,833(1.8 \%)$ & 0.02 \\
\hline Median (IQR) gestational age (weeks) & $38(37-40)$ & $39(38-40)$ & $<0.001$ \\
\hline
\end{tabular}

$\mathrm{SD}$, standard deviation; IQR, interquartile range

\section{Discussion}

In our population-based study, we found that women living with HIV were less likely to receive adequate prenatal care than women living without HIV. We also found that, among women with HIV, recent immigrants from Africa and the Caribbean were markedly less likely to receive adequate prenatal care than non-immigrant women. Similar findings have been described in other jurisdictions with universal access to prenatal care. Specifically, women with HIV originally from Africa were at heightened risk of late initiation of prenatal care relative to referent populations in separate studies conducted in the UK/Ireland and France, although late diagnosis of HIV accounted for this finding in the latter study $[39,40]$.

Our findings build on previous research examining the adequacy of prenatal care among women with HIV. In a
U.S. study examining 2254 singleton births to women with HIV, only one-third received adequate prenatal care according to a utilization index, with $20 \%$ reporting no prenatal care before delivery [28]. Similar results were noted in a study describing prenatal care utilization by women with HIV in 4 U.S. states, in that $39 \%$ of women did not receive adequate prenatal care [41]. However, these studies were not population-based in nature and were conducted prior to the availability of modern antiretroviral therapy. Moreover, our study was conducted in a setting of universal coverage for prenatal care. Consequently, the receipt of prenatal care should not be influenced by health insurance status.

We speculate that our findings are related to a series of inter-related social and structural barriers to care for women living with HIV during the preconception and 
Table 2 Regression models of predictors of adequate prenatal care (R-GINDEX)

\begin{tabular}{|c|c|c|}
\hline \multirow[t]{2}{*}{ Covariate } & \multirow{2}{*}{$\begin{array}{l}\text { Crude Odds Ratio } \\
\text { (95\% Confidence Interval) }\end{array}$} & \multirow{2}{*}{$\begin{array}{l}\text { Adjusted Odds Ratio } \\
\text { (95\% Confidence Interva }\end{array}$} \\
\hline & & \\
\hline Women living with HIV & 0.74 (0.63 to 0.88$)$ & $0.74(0.62$ to 0.88$)$ \\
\hline \multicolumn{3}{|l|}{ Age } \\
\hline 18 to 34 years & 1.00 & 1.00 \\
\hline 35 to 49 years & 0.72 (0.72 to 0.73 ) & 0.74 (0.74 to 0.75$)$ \\
\hline \multicolumn{3}{|l|}{ Aggregated Diagnosis Groups } \\
\hline 0 to 5 & 1.00 & 1.00 \\
\hline 6 to 10 & $1.52(1.51$ to 1.54$)$ & $1.53(1.52$ to 1.55$)$ \\
\hline 11 or more & 2.16 (2.09 to 2.23 ) & $2.20(2.12$ to 2.27$)$ \\
\hline \multicolumn{3}{|l|}{ Immigration Status } \\
\hline Non-immigrant & 1.00 & 1.00 \\
\hline Non-recent immigrant, Africa or Caribbean & 0.80 (0.78 to 0.83$)$ & 0.81 (0.79 to 0.83 ) \\
\hline Non-recent immigrant, other world regions & $1.05(1.04$ to 1.06$)$ & $1.02(1.00$ to 1.03$)$ \\
\hline Recent immigrant, Africa or Caribbean & $0.62(0.60$ to 0.65$)$ & 0.65 (0.63 to 0.68$)$ \\
\hline Recent immigrant, other world regions & 0.78 (0.78 to 0.79$)$ & 0.81 (0.80 to 0.82$)$ \\
\hline \multicolumn{3}{|l|}{ Material Deprivation Income Quintile } \\
\hline 1 (lowest) & 1.00 & 1.00 \\
\hline 2 & 0.85 (0.84 to 0.86$)$ & 0.85 (0.84 to 0.86$)$ \\
\hline 3 & $0.76(0.75$ to 0.76$)$ & 0.76 (0.76 to 0.77$)$ \\
\hline 4 & 0.69 (0.68 to 0.69$)$ & 0.70 (0.69 to 0.71$)$ \\
\hline 5 & 0.62 (0.61 to 0.63 ) & $0.63(0.62$ to 0.64$)$ \\
\hline \multicolumn{3}{|l|}{ Residential Instability Quintile } \\
\hline 1 (lowest) & 1.00 & 1.00 \\
\hline 2 & 0.98 (0.97 to 0.99 ) & 1.01 (1.00 to 1.02 ) \\
\hline 3 & 0.90 (0.89 to 0.91$)$ & 0.99 (0.98 to 1.01$)$ \\
\hline 4 & 0.83 (0.82 to 0.84 ) & 1.00 (0.99 to 1.01$)$ \\
\hline 5 & 0.83 (0.82 to 0.84 ) & 1.01 (1.00 to 1.02$)$ \\
\hline Multiple birth & 4.12 (3.99 to 4.25$)$ & 3.97 (3.84 to 4.10$)$ \\
\hline Parity & 0.87 (0.86 to 0.87 ) & 0.84 (0.83 to 0.85 ) \\
\hline
\end{tabular}

prenatal periods. This reasoning is supported by earlier literature documenting stigma, discrimination, difficulty for newcomers navigating a foreign health care system and lack of preconception counselling for women living with HIV, each of which may act as components in one or more causal mechanisms that culminate in the outcome of inadequate prenatal care [17-27].

Our findings have important implications for needs assessment and programme planning. In Canada and other developed countries, great strides have been made in ensuring that the overwhelming majority of women with HIV receive antiretroviral therapy during pregnancy. Consequently, the rate of perinatal HIV transmission among women who receive antenatal is $1 \%$ [42]. However, substantial non-infectious neonatal morbidity exists in the context of HIV infection in Ontario, with risks of low birth weight, preterm birth and small for gestational age births among women with HIV exceeding those of non-infected women by $90 \%, 76 \%$ and $43 \%$, respectively [43]. Because research has shown that improving access to prenatal care is associated with reduced risks of these adverse neonatal outcomes in women with HIV [27], it is important to ensure that additional data are gathered from these women which inform the development of interventions that promote timely linkage to and retention in prenatal care. This may be especially salient for those women originally from Africa and the Caribbean. However, in light of our findings that approximately $40 \%$ of women living with HIV in Ontario who have had children live in the most deprived and unstable neighborhoods in the province, it is unlikely that narrowly targeted interventions which only increase access to prenatal medical services will be sufficient for addressing the social and environmental determinants of 
Table 3 Regression models of initiation of prenatal care in the first trimester

\begin{tabular}{|c|c|c|}
\hline \multirow[t]{2}{*}{ Covariate } & Crude Odds Ratio & Adjusted Odds Ratio \\
\hline & (95 \% Confidence Interval) & (95\% Confidence Interval) \\
\hline Women living with HIV & 0.45 (0.38 to 0.53$)$ & 0.51 (0.43 to 0.60$)$ \\
\hline \multicolumn{3}{|l|}{ Age } \\
\hline 18 to 34 years & 1.00 & 1.00 \\
\hline 35 to 49 years & 0.79 (0.78 to 0.80$)$ & 0.82 (0.81 to 0.83 ) \\
\hline \multicolumn{3}{|l|}{ Aggregated Diagnosis Groups } \\
\hline 0 to 5 & 1.00 & 1.00 \\
\hline 6 to 10 & 1.43 (1.41 to 1.44$)$ & $1.46(1.45$ to 1.47$)$ \\
\hline 11 or more & $1.57(1.51$ to 1.63$)$ & $1.63(1.57$ to 1.70$)$ \\
\hline \multicolumn{3}{|l|}{ Immigration Status } \\
\hline Non-immigrant & 1.00 & 1.00 \\
\hline Non-recent immigrant, Africa or Caribbean & 0.64 (0.62 to 0.66$)$ & 0.67 (0.65 to 0.69$)$ \\
\hline Non-recent immigrant, other world regions & 0.95 (0.93 to 0.96$)$ & 0.93 (0.91 to 0.94$)$ \\
\hline Recent immigrant, Africa or Caribbean & 0.46 (0.45 to 0.48$)$ & 0.52 (0.50 to 0.53$)$ \\
\hline Recent immigrant, other world regions & 0.64 (0.64 to 0.65$)$ & 0.68 (0.67 to 0.69$)$ \\
\hline \multicolumn{3}{|l|}{ Material Deprivation Income Quintile } \\
\hline 1 (lowest) & 1.00 & 1.00 \\
\hline 2 & 0.84 (0.83 to 0.85$)$ & 0.85 (0.83 to 0.86$)$ \\
\hline 3 & 0.73 (0.72 to 0.74$)$ & 0.75 (0.74 to 0.76$)$ \\
\hline 4 & 0.63 (0.63 to 0.64$)$ & 0.67 (0.66 to 0.68$)$ \\
\hline 5 & 0.54 (0.54 to 0.55$)$ & 0.59 (0.58 to 0.60$)$ \\
\hline \multicolumn{3}{|l|}{ Residential Instability Quintile } \\
\hline 1 (lowest) & 1.00 & 1.00 \\
\hline 2 & 1.01 (0.99 to 1.02$)$ & $1.03(1.02$ to 1.04$)$ \\
\hline 3 & 0.92 (0.91 to 0.93$)$ & $1.02(1.01$ to 1.04$)$ \\
\hline 4 & 0.80 (0.79 to 0.81$)$ & 1.00 (0.99 to 1.02$)$ \\
\hline 5 & 0.73 (0.72 to 0.74$)$ & 0.95 (0.94 to 0.96$)$ \\
\hline Multiple birth & 1.59 (1.54 to 1.64$)$ & 1.49 (1.44 to 1.54$)$ \\
\hline Parity & $0.96(1.54$ to 1.64$)$ & 0.92 (0.83 to 0.93$)$ \\
\hline
\end{tabular}

perinatal health in these women [44-46]. Many women living with HIV who are pregnant may also have immigration, housing, legal and social support needs which must also be addressed. Further qualitative research is planned with the community of women living with HIV to evaluate and explore the nature of prenatal services required by women with HIV.

Several limitations of our study merit emphasis. First, as with other utilization indices, the R-GINDEX is a quantitative measure of prenatal care use and does not address the quality or content of care received. Second, prenatal care provided through midwives, community support programs, nurses or physicians who do not bill OHIP is not recorded in our administrative databases. It is therefore possible that the adequacy of prenatal care was under-estimated in our study, particularly among women originally from Africa and the Caribbean. Third, we could not ascertain births among women who were refugee claimants or who did not have provincial health insurance. Fourth, the R-GINDEX is based on the American College of Obstetricians and Gynecologists recommendations for the number of visits for low risk pregnant women. The applicability of this measure to women living with HIV is unknown. Finally, our databases did not include information about other determinants of prenatal health use including substance use, maternal education and intendedness of pregnancy $[26,35]$.

\section{Conclusions}

We identified meaningful disparities in the receipt of adequate prenatal care between women with and without HIV and among women with HIV originally from Africa and the Caribbean relative to Canadian-born women. Because understanding and addressing barriers to care is 
complex and multifaceted, involving women with HIV in research and policy initiatives which facilitate the use of prenatal care and characterize the content of prenatal care required to address the social determinants of pregnancy outcomes is warranted.

\section{Additional files}

Additional file 1: Table S1. R-GINDEX prenatal care categories for 28-, 32-, 36- and 40-week deliveries.

Additional file 2: Table S2. Demographic characteristics of pregnancies among women with HIV, by immigration status.

Additional file 3: Table S3. Multivariable analyses of predictors of adequate prenatal care and initiation of prenatal care in first trimester among women with HIV.

\section{Abbreviations}

HIV: Human immunodeficiency virus; OHIP: Ontario health insurance plan; R-GINDEX: Revised-graduated prenatal care utilization index; aOR: Adjusted odds ratio; Cl: Confidence interval.

\section{Competing interests}

The authors declare that they have no competing interests.

\section{Authors' contributions}

RN, EM, MRL, MY, AMB, JR, KIM, WET, JB, RHG and TA contributed to the concept and design of the study. TA, RN and EM, RN, EM, MRL, MY, AMB, JR, $\mathrm{KIM}, \mathrm{WET}, J \mathrm{~B}, \mathrm{RHG}$ and TA were involved in the analysis and interpretation of the data. RN and TA drafted the manuscript. EM, MRL, MY, AMB, JR, KIM, WET, JB and RHG were involved in critical revision of the manuscript. RN, EM, MRL, MY, AMB, JR, KIM, WET, JB, RHG and TA approved the manuscript submitted for publication. TA, EM and RN provided administrative, technical or material support. TA is the guarantor for the manuscript.

\section{Acknowledgements}

This project was supported by a research operating grant from the Ontario HIV Treatment Network (grant number ROG G768) and by the Institute for Clinical Evaluative Sciences (ICES), which is funded by an annual grant from the Ontario Ministry of Health and Long-Term Care (MOHLTC). The sponsors had no role in the design or conduct of the study; in the collection, analysis or interpretation of the data; or in the preparation, review or approval of the manuscript. The opinions, results and conclusions reported in this paper are those of the authors and are independent from the funding source. No endorsement by ICES or the Ontario MOHLTC is intended or should be inferred. Tony Antoniou is supported by a New Investigator Award from the Canadian Institutes for Health Research-Ontario HIV Treatment Network. Mona Loutfy is the recipient of salary support from Women's College Hospital, the University of Toronto and the Women's College Research Institute. Ahmed M. Bayoumi is supported by a Canadian Institutes for Health Research / Ontario Ministry of Health and Long-Term Care Applied Chair in Health Services and Policy Research. Janet Raboud is supported by an Ontario HIV Treatment Network Career Scientist Award and the Skate the Dream Fund, Toronto and Western Hospital Foundation. Richard H. Glazier is a Clinician Scientist in the Department of Family and Community Medicine of St. Michael's Hospital and the University of Toronto.

\section{Author details}

${ }^{1}$ Institute for Clinical Evaluative Sciences, Toronto, Ontario, Canada. ${ }^{2}$ Institute of Health Policy, Management and Evaluation, University of Toronto, Toronto, Ontario, Canada. ${ }^{3}$ Department of Medicine, University of Toronto, Toronto, Ontario, Canada. ${ }^{4}$ Women's College Research Institute, Women's College Hospital, Toronto, Ontario, Canada. ${ }^{5}$ Li Ka Shing Knowledge Institute, St. Michael's Hospital, Toronto, Ontario, Canada. ${ }^{6}$ Centre for Research on Inner City Health, St. Michael's Hospital, Toronto, Ontario, Canada. ${ }^{7}$ Department of Obstetrics and Gynecology, St. Michael's Hospital and University of Toronto, Toronto, Ontario, Canada. ${ }^{8}$ Toronto General Research Institute, University Health Network, Toronto, Ontario, Canada. ${ }^{9}$ Dalla Lana School of Public
Health, University of Toronto, Toronto, Ontario, Canada. ${ }^{10}$ Women's Health in Women's Hands Community Health Centre, Toronto, Ontario, Canada. ${ }^{11}$ Children's Hospital of Eastern Ontario and University of Ottawa, Ottawa, Ontario, Canada. ${ }^{12}$ Department of Family and Community Medicine, St. Michael's Hospital and University of Toronto, Toronto, Ontario, Canada.

Received: 12 August 2014 Accepted: 14 May 2015

Published online: 29 May 2015

\section{References}

1. Alexander GR, Kotelchuk M. Assessing the role and effectiveness of prenatal care: history, challenges and directions for future research. Public Health Rep. 2001;116:306-16.

2. Society of Obstetricians and Gynaecologists of Canada. SOGC Clinical Practice Guidelines: Health Beginnings: Guidelines for care during pregnancy and childbirth. Volume 71. Ottaa, SOGC; 1998.

3. Homan RK, Korenbrot CC. Explaining variation in birth outcomes of Medicaid-eligible women with variation in the adequacy of prenatal support services. Med Care. 1998:36:190-201.

4. El-Mohandes A, Herman AA, Nabil El-Khorazaty M, Katta PS, White D, Grylack L. Prenatal care reduces the impact of illicit drug use on perinatal outcomes. J Perinatol. 2003;23:354-60.

5. Petrou S, Kupek E, Vause S, Maresh M. Antenatal visits and adverse perinatal outcomes: results from a British population-based study. Eur J Obstet Gynecol Reprod Biol. 2003;106:40-9.

6. Krueger PM, Scholl TO. Adequacy of prenatal care and pregnancy outcome. J Am Osteopath Assoc. 2000;100:485-92.

7. Laditka SB, Laditka JN, Mastanduno MP, Lauria MR, Foster TC. Potentially avoidable maternity complications: an indicator of access to prenatal and primary care during pregnancy. Women Health. 2005;41:1-26.

8. American Academy of Pediatrics and American College of Obstetricians and Gynecologists. Guidelines for perinatal care. 6th ed. Elk Grove Village (IL): AAP; Washington, DC: ACOG; 2007.

9. Kogan MD, Martin JA, Alexander GR, Kotelchuck M, Ventura SJ, Frigoletto FD. The changing pattern of prenatal care utilization in the United States, 1981-1995, using different prenatal care indices. JAMA. 1998;279:1623-8.

10. Delvaux T, Buekens P, Godin I, Boutsen M. Barriers to prenatal care in Europe. Am J Prev Med. 2001;21:52-9.

11. Sword W. Prenatal care use among women of low income: a matter of Taking Care of Self'. Qual Health Res. 2003;13:319-32.

12. Daniels P, Noe GF, Mayberry R. Barriers to prenatal care among Black women of low socioeconomic status. Am J Health Behav. 2006;30:188-98.

13. Downe S, Finlayson K, Walsh D, Lavender T. 'Weighing up and balancing out': a meta-syntehsis of barriers to antenatal care for marginalized women in high-income countries. BJOG. 2009;116:518-29.

14. Kupek E, Petrou S, Vause S, Maresh M. Clinical, provider and sociodemographic predictors of late initiation of antenatal care in England and Wales. BJOG. 2002;109:265-73.

15. Trinh LT, Rubin G. Late entry to antenatal care in New South Wales. Australia Reprod Health. 2006:3:8

16. Petrou S, Kupek E, Vause S, Maresh M. Clinical, provider and sociodemographic determinants of the number of antenatal visits in England and Wales. Soc Sci Med. 2001;52:1123-34.

17. Heaman M, Bayrampour $H$, Kingston D, et al. Migrant women's utilization of prenatal care: a systematic review. Matern Child Health J. 2013;17:816-36.

18. Boerleider AW, Wiegers TA. Mannïen, Francke AL. Devillé WL Factors affecting the use of prenatal are by non-western women in industrialized western countries: a systematic review BMC Pregnancy Childbirth. 2013;13:81.

19. Schuster MA, Collins R, Cunningham WE. Perceived discrimination in clinical care in a nationally representative sample of HIV-infected adults receiving health care. J Gen Intern Med. 2005;20:807-13.

20. Napravnik S, Royce R, Walter E, Lim W. HIV-1 infected women and prenatal care utilization: barriers and facilitators. AIDS Patient Care STDs. 2000;14:411-20.

21. Ion A, Greene $S$, Mellor $K$, et al. Perinatal care experiences of mothers living with HIV in Ontario: what works and what doesn't. Can J Infect Dis Med Microbiol 2014, 25(Suppl A):105A.

22. Loutfy MY, Blitz S, Zhang Y, et al. Self-reported preconception care of HIV-positive women of reproductive potential: a retrospective study. J Int Assoc Provid AIDS Care 2013 Aug 5. [Epub ahead of print].

23. Panozzo L, Battegay M, Friedl A, Vernazza PL, Swiss HIV. Cohort Study. High risk behaviour and fertility desires among heterosexual HIV-positive patients 
with a serodiscordant partner - two challenging issues. Swiss Med Wkly. 2003;133:124-7.

24. Finocharrio-Kessler S, Dariotis JK, Sweat MD, et al. Do HIV-infected women want to discuss reproductive plans with providers, and are those conversations occurring? AIDS Patient Care STDs. 2010;24:317-23.

25. Loutfy MR, Raboud JM, Wong J, et al. High prevalence of unintended pregnancies in HIV-positive women of reproductive age in Ontario, Canada: a retrospective study. HIV Med. 2012;13:107-17.

26. Dibaba Y, Fantahun M, Hindin MJ. The effects of pregnancy intention on the use of antenatal care services: systematic review and meta-analysis. Reprod Health. 2013;10:50.

27. Turner BJ, Newschaffer CJ, Cocroft J, Fanning TR, Marcus S, Hauck WW. Improved birth outcomes among HIV-infected women with enhanced Medicaid prenatal care. Am J Public Health. 2000;90:85-91.

28. Turner BJ, McKee LJ, Silverman NS, Hauck WW, Fanning TR, Markson LE, Prenatal care and birth outcomes of a cohort of HIV-infected women. J Acquir Immune Defic Syndr Hum Retrovirol. 1996;12:259-67.

29. Antoniou T, Zagorski B, Macdonald EM, et al. Trends in live birth rates and adverse neonatal outcomes among HIV-positive women in Ontario, Canada, 2002-2009: a descriptive population-based study. Int J STD AIDS. 2014:25:960-6.

30. Antoniou T, Zagorski B, Loutfy MR, Strike C, Glazier RH. Validation of case-finding algorithms derived from administrative data for identifying adults living with human immunodeficiency virus infection. PLoS One. 2011;6, e21748.

31. Ray JG, Urquia ML, Berger H, Vermeulen MJ. Maternal and neonatal separation and mortality associated with concurrent admissions to intensive care units, CMAJ. 2012;184:E956-62.

32. Vigod SN, Kurdyak PA, Dennis $\mathrm{CL}$, et al. Maternal and newborn outcomes among women with schizophrenia: a retrospective population-based cohort study. BJOG. 2014;121:566-74.

33. Alexander GR, Kotelchuk M. Quantifying the adequacy of prenatal care: a comparison of indices. Public Health Rep. 1996;111:408-18.

34. Hueston WJ, Gilbert GE, Davis L, Sturgill V. Delayed prenatal care and the risk of low birth weight delivery. J Community Health. 2003;28:199-208.

35. Weir S, Posner HE, Zhang J, Willis G, Baxter JD, Clark RE. Predictors of prenatal and postpartum care adequacy in a Medicaid managed care population. Womens Health Issues. 2011;21-4:277-85.

36. Nothnagle M, Marchi K, Egerter S, Braveman P. Risk factors for late or no prenatal care following Medicaid expansions in California. Matern Child Health J. 2000;4:251-9.

37. Johns Hopkins ACG Case-Mix Adjustment System [http://www.acg.jhsph.org]

38. Matheson FI, Dunn JR, Smith KLW, Moineddin R, Glazier RH. Development of the Canadian Marginalization Index: a new tool for the study of inequality. Can J Public Health. 2012;103 Suppl 2:S12-6.

39. Tariq S, Elford J, Cortina-Borja M. Tooky PA; National Study of HIV in Pregnancy and Childhood. The association between ethnicity and late presentation to antenatal care among pregnant women living with HIV in the UK and Ireland. AIDS Care. 2012;24:978-85.

40. Jasseron C, Mandelbrot $L$, Tubiana R, et al. Prevention of mother-to-child HIV transmission: similar access for sub-Sahara African immigrants and for French women? AIDS. 2008;22:1503-11.

41. Wilson TE, Ickovics JR, Royce R, Fernandez MI, Lampe M, Koenig LJ. Prenatal care utilization and the implementation of prophylaxis to pevent perinatal HIV-1 transmission. Matern Child Health J. 2004;8:13-8.

42. Forbes JC, Alimenti AM, Singer J, et al. A national review of vertical HIV transmission. AIDS. 2012;26:757-63.

43. Macdonald EM, Ng R, Bayoumi AM, et al. Adverse neonatal outcomes among women living with HIV in Ontario: a population-based study. J Obstet Gynaecol Can. 2015:37:302-9.

44. Misra DP, Guyer B. Benefits and limitations of prenatal care: from counting visits to measuring content. JAMA. 1998;279:1661-2.

45. Pies C, Parthasarathy P, Posner SF. Integrating the Life Course Perspective into a local maternal and child health program. Matern Child Health J. 2011;16:649-55.

46. Misra DP, Guyer B, Allston A. Integrated perinatal health framework: a multiple determinants model with a Life Span approach. Am J Prev Med. 2003;65-75.

\section{Submit your next manuscript to BioMed Central and take full advantage of:}

- Convenient online submission

- Thorough peer review

- No space constraints or color figure charges

- Immediate publication on acceptance

- Inclusion in PubMed, CAS, Scopus and Google Scholar

- Research which is freely available for redistribution 